\title{
Between-species facilitation by male fig wasps in shared figs
}

\author{
by Wang, R., Segar, S.T., Harper, M., Yu, H., Quinnell, \\ R.J. and Compton, S.G.
}

Copyright, publisher and additional information: this is the author accepted manuscript. The final published version (version of record) is available online via Wiley. This article may be used for non-commercial purposes in accordance with Wiley Terms and Conditions for Self-Archiving.

Please refer to any applicable terms of use of the publisher.

DOI: https://dx.doi.org/10.1111/een.12201

Wang, R., Segar, S.T., Harper, M., Yu, H., Quinnell, R.J. and Compton, S.G. 2015. Between-species facilitation by male fig wasps in shared figs. Ecological Entomology, 40(4), pp.428-436. 


\section{Between-species facilitation by male fig wasps in shared figs}

Rong Wang ${ }^{1}$, Simon T. Segar ${ }^{2}$, Maximilian Harper ${ }^{1}$, Hui Yu ${ }^{3}$, Stephen G.

Compton ${ }^{1,4 *}$

* Author for correspondence: s.g.a.compton@leeds.ac.uk

${ }^{1}$ School of Biology, University of Leeds, Leeds LS2 9JT, UK.

${ }^{2}$ Faculty of Science, University of South Bohemia, Branisovska 31, 37005 Ceske

Budejovice, Czech Republic

${ }^{3}$ South China Botanical Garden, the Chinese Academy of Sciences, Guangzhou 510650,

China.

${ }^{4}$ Department of Zoology \& Entomology, Rhodes University, Grahamstown 6140, South Africa. 


\section{Abstract:}

1. Facilitation, where one species helps another without cost or benefit to itself, is recorded from diverse plant-insect interactions, including pollination and herbivory. We investigated the significance of facilitation resulting from the behaviour of pollinator fig wasps inside figs shared with other species. Fig wasp females emerge from natal figs via exit holes dug by pollinator and some other fig wasp males. When no males are present the females struggle to escape and may die.

2. Ficus microcarpa is a widely-established invasive fig tree from SE Asia. Its pollinator is absent in South Africa, so the tree cannot reproduce, but two nonpollinating fig wasps (NPFW) Walkerella microcarpae and Odontofroggatia galili occupy its figs. We compared abundance patterns of the two NPFW and the proportion of male-free figs in South Africa, Spain (where the pollinator is introduced), and in China, where the native fig wasp community is diverse, to determine the consequences of reduced facilitation for insect survival.

3. The presence of pollinators in Spain allowed most NPFWs to develop in figs containing males. Far more male-free figs were present in South Africa, elevating mortality rates among female NPFW. Facilitation of female release by males of the more common NPFW species nonetheless benefitted the rarer species.

4. In the absence of pollinators (and specialist parasitoids) selection in South Africa should favour greater aggregation of NPFW offspring into a smaller numbers of figs, a preference for shared figs and less female-biased offspring sex ratios. The system provides an opportunity to investigate the plasticity of these traits. 
Key-words: Agaonidae, brood size, Allee effect, density compensation, Ficus, interspecific facilitation, mutualism 


\section{Introduction}

Facilitation, where one species benefits another without cost or benefit to itself, has been recorded among species involved in a range of plant-insect interactions, involving predators (Losey \& Denno 1998), pollinators (Ghazoul 2006), herbivores (Soler et al. 2014) and detritivores (Starzomski, Suen \& Srivastava 2010). Individuals of the same species often also help others, most notably in insect societies and where males and females necessarily co-operate to reproduce, but here, as in inter-specific mutualisms, both parties benefit. The extent of facilitation depends on frequency of co-occurrence, and the rarity or absence of facilitators can cause problems for dependent species, in the same way that reduced intraspecific cooperation can generate Allee effects when densities of conspecifics are low (Allee et al. 1949; Courchamp, Berec \& Gascoigne 2008, Tobin, Berec \& Liebhold 2011).

Plants and animals are increasingly being introduced into novel environments where the mix of species with which they interact are a sub-set of those in their natural range, or entirely different (Tylianakis et al. 2008). Although most non-indigenous species fail to become established, those that do include a small proportion which eventually become economic pests or invasive aliens, sometimes because they have benefited by escaping from their natural enemies (Keane \& Crawley 2002). Generalist species are expected to be able to establish more easily in novel environments, because they are not dependent on specific resources or co-habitants, whereas some specialist herbivores, for example, are entirely dependent on the presence of their particular food plant, as are plant species that require specific pollinators (Richardson et al. 2000).

Ficus (Moraceae) is one of the most diverse plant genera in tropical and sub-tropical forests, with over 800 species (Harrison 2005). Its obligate mutualism with pollinating fig wasps (Agaonidae) (Wiebes 1979) means that each fig tree species is dependent for sexual reproduction on one or a small number of host-specific insects whose larvae 
develop inside galled ovules within the plants' unique inflorescences - figs. In addition to the pollinators, figs are also exploited by many non-pollinating fig wasp (NPFW) species that can also be host-plant specific. Often pollinators and several NPFW species share individual figs, where the latter have a negative effect on their host plants by killing or competing with pollinators and also reducing seed production (Kerdelhué \& Rasplus 1996). Many fig tree species have been introduced outside their native range, and when their particular pollinators are also introduced there is the potential for the trees to reproduce, and even become invasive (Starr, Starr \& Loope 2003; Miao et al. 2011).

Adult male pollinator fig wasps lack wings and spend all or most of their lives inside their natal figs. After mating inside the figs, they cooperate with conspecific males to chew an exit hole through the fig wall, through which the females can escape and then fly off in search of immature figs to lay their eggs (Suleman, Raja \& Compton 2012). Emergence from natal figs through one or a small number of shared exit holes is in contrast to more typical large galls with multiple chambers seen on other plants, where adult male and female wasps independently release themselves through holes they chew themselves (László \& Tóthméréz 2008). The likelihood that there will be no adult male pollinators in a fig to cut an exit hole is increased by their strongly female-biased sex ratios and the often high mortality rates caused by NPFW. 'Insurance males' may be one response to this problem (Heimpel 1994; Moore et al. 2005), as is the placement of galls containing male pollinators, which are often located towards the centre of figs, where deaths due to parasitoid NPFW are reduced (Dunn et al. 2008; Yu \& Compton 2012).

Female NPFWs often also depend on pollinator males to generate the exit holes that allow them to escape from their natal figs, though males of some NPFW can independently produce their own exit holes. Even if the NPFW males can chew exit holes they may be less effective than pollinator males (Suleman, Raja \& Compton 2012), 
and are often rare or absent because of female biased sex ratios and because NPFW are often present at lower densities than the pollinators within occupied figs (Fellowes, Compton \& Cook 1999). Female fig wasps that develop in figs that contain no male fig wasps, particularly no male pollinators, are likely to remain trapped in their natal figs, and die there. Whether they remain trapped will depend on the mix of species occupying each fig, their sex ratios and their combined densities .

F. microcarpa is a widely-planted Asian fig tree, especially in Mediterranean and subtropical environments. The tree's pollinator has also been widely introduced, together with several NPFW, of which two gall-forming species, Walkerella microcarpae Bouček and Odontofroggatia galili Wiebes are the most widespread. Exceptionally, these NPFW have colonised South Africa in the absence of the pollinator, so they cannot utilise pollinator males to aid their escape from the figs (van Noort, Wang \& Compton 2013). Holes made by males of one of the NPFW can nonetheless benefit females of both species. We investigated the facilitation of release of female wasps by male pollinators and NPFW that share figs of F. microcarpa. Specifically, we compared the abundance of the two NPFW and the proportion of male-free figs in South Africa with those in Spain (where both NPFWs have been introduced together with the tree's pollinator, but the fig wasp community is depauperate) and in southern China, where a diverse fig wasp community is present. We aimed to answer the following questions: Do female fig wasps fail to emerge from their natal figs if they get no help of male fig wasps? If so, what is the extent of facilitation of female NPFW emergence by pollinator males? Can NPFW males also facilitate the release of females belonging to other NPFW species? And does the novel community composition within the insect's introduced range generate novel selection pressures on the insects?

\section{Materials and methods}

\section{Study species}

F. microcarpa L. is a monoecious fig tree species with a wide natural distribution that 
extends from India to China and Australia (Berg \& Corner 2005). It has also been introduced into many tropical and subtropical areas around the world, where it can become invasive (Nadel, Frank \& Knight 1992; Beardsley 1998; Caughlin et al. 2012). Its small figs (syconia) are located in the leaf axils (Berg \& Corner 2005). Birds are the main dispersers of the seeds, with ants acting as secondary seed dispersal agents (Kaufmann et al. 1991; Shanahan et al. 2001).

The host-specific pollinators of F. microcarpa are currently grouped under Eupristina verticillata Waterston, which comprises several genetically distinct but morphologically similar species (Sun et al. 2011). Only one of these taxa has been detected outside the plant's native range (A Cruaud and J-Y Rasplus Pers. Comm.). In addition, there is a non-pollinating Eupristina species that no longer actively pollinates the figs and has only been recorded from SW China (J-Y Rasplus, Pers. Comm.). At least 20 species of NPFW develop inside the figs of F. microcarpa (Bouček 1988; Beardsley 1998; Chen, Chuang \& Wu 1999; Feng \& Huang 2010). Unlike the pollinators, the females of all these species lay their eggs from the outer surface of the figs. Some species are ovule-gallers and others are parasitoids of ovule-galling NPFW and the pollinator. One NPFW is an obligate seed predator (Wang et al. 2014). As with fig wasps in general, a single offspring develops within each seed or galled ovule.

Walkerella microcarpae Bouček (Pteromalidae, Otitesellinae) is one of the two most widely-introduced NPFW associated with F. microcarpa. Its larvae develop inside galled ovules, like those of the pollinator. The species displays strong sexual dimorphism, with fully-winged females and wingless males that have large jaws that they use for fighting with each other. W. microcarpae can develop successfully in figs that contain no other fig wasp species, with mating taking place within and outside the figs (Figueiredo \& Motta 1993). It is only known from figs of F. microcarpa. Native range records include mainland China and Papua New Guinea (van Noort, Wang \& Compton 2013). 
Odontofroggatia galili Wiebes (Epichrysomallinae, a currently unplaced sub-family) is the other very widely introduced NPFW associated with F. microcarpa (Stange \& Knight 1987; Compton 1989) and has a wide natural distribution from China to Australia (Bouček 1988). It has been recorded mainly from figs of F. microcarpa and can again develop successfully in F. microcarpa figs that lack other species (Galil \& Copland 1981). Both males and females have winged adults, and most mating probably takes place outside their natal figs.

The males of both NPFW species are capable of producing exit holes through the fig wall to allow conspecific females to escape and disperse. O. galili is noticeably larger than W. microcarpae, so exit holes produced by the former are clearly suitable for females of the latter species. Exit holes generated by W. microcarpae males may need to be widened by the O. galili females before they can escape. Irrespective of species, a single exit hole is normally produced and shared by the females of both NPFW and the pollinator.

\section{Sample sites}

Mature figs of F. microcarpa were sampled in South Africa, Spain and China in 2011 and 2012. W. microcarpae and O. galili were present in the figs collected from all three countries, but E. verticillata was absent from the South African collections.

In South Africa F. microcarpa was planted as an ornamental tree on roadsides and shopping malls in Port Elisabeth and Grahamstown. Port Elisabeth is coastal and Grahamstown is approximately $43 \mathrm{~km}$ inland (Table1). The cities are approximately $130 \mathrm{~km}$ apart. They have a semi-arid Mediterranean climate, with unpredictable rainfall that averages about $460 \mathrm{~mm}$ annually at the coast. F. microcarpa in Palma, on the coast of Majorca (Spain) was planted on roadsides and in small parks. Majorca is the largest island in the Balearic archipelago and has a typical Mediterranean climate with mild and relatively rainy winters and hot, dry summers. Annual rainfall is about $330 \mathrm{~mm}$. 
Guangzhou, a city within the native range of F. microcarpa, but where the tree is also extensively planted, is located near the southeast coast of China and has a humid subtropical climate with hot and wet summers, mild, relatively dry winters and an annual rainfall of about $2000 \mathrm{~mm}$.

\section{Sampling methods}

We haphazardly collected mature figs without fig wasp exit holes (late C/early D phases sensu Galil \& Eisikowitch (1968)) from the trees and stored them in ethanol (Table 1).The figs were later divided into quarters and soaked in water to soften the galled ovules before being examined under a dissecting microscope. Aborting figs superficially resemble late $\mathrm{C}$ phase figs. Any figs mistakenly collected that had not been colonised by fig wasps were not considered further. The numbers of male and female flowers and fig wasps in the remaining figs were recorded. The fig wasps were extracted from their galls and stored in 95\% ethanol. They were identified using mainly Chen, Chuang \& Wu (1999) and Feng \& Huang (2010). In August 2012 we also collected fallen figs from the ground below ten F. microcarpa growing in Grahamstown. We recorded the identities and sexes of any dead fig wasp offspring that were inside and whether or not an exit hole was present.

\section{Statistical analyses}

Generalized linear mixed models (GLMMs) were generated in package lme4 version 1.0-5 (Bates et al. 2013) in R 3.0.0 (R Development Core Team 2013). Likelihood ratio tests were used to estimate the significance of fixed effects, and pair-wise comparisons between levels within fixed effects were obtained using multiple tests with Bonferroni corrections. Crop identity was set as the random effect in all analyses. We compared fig wasp species richness, occupancy rates, and abundance of E. verticillata, O. galili and W. microcarpae using GLMMs that assumed either binomial (only for occupancy rate) or Poisson distributions of residuals. Occupancy rates were calculated as the proportion of ovules containing adult fig wasp offspring as a proportion of the total number of 
female flowers in a fig. The abundance of each fig wasp species per fig was calculated based only on those figs where each was present.

Using figs from Grahamstown (South Africa), we tested whether females of the two NPFW species can release themselves without the help of male fig wasps by comparing the proportion of fallen figs containing trapped females with the proportion of on-tree figs containing only females of either species using GLMMs that assumed binomial distributions of residuals.

Between-country differences in the proportions of figs containing no males of any species and those figs that contained O. galili or W. microcarpae females but no conspecific males were examined using GLMMs assuming binomial distribution of residuals. In addition, GLMMs assuming binomial distribution of residuals were used to examine the relationship between the proportion of figs containing O. galili or W. microcarpae females but no conspecific males and the abundance of each species, and to test whether this varied among countries.

In Spain and China, facilitation among NPFW species was tested by regressing numbers of NPFW males on NPFW species richness using GLMMs assuming Poisson distribution of residuals. In South Africa, interspecific facilitation was tested using GLMMs assuming binomial distribution of residuals that compared the proportion of figs containing either NPFW species but no conspecific males and the proportion of figs containing either species but no males of any species. We could not carry out equivalent regression analyses in South Africa because only two NPFW species were present.

\section{Results}

Fig wasp communities 
A total of 502 figs from 30 trees were collected in South Africa, Spain and China (Table 1). The native-range fig wasp faunas in the Chinese F. microcarpa figs were diverse, comprising the pollinator E. verticillata, O. galili, W. microcarpae and a further 12 NPFW species that included ovule-gallers and parasitoids. The three species were also present in Spain, together with Micranisa degastris Chen, an otiteselline that also galls the ovules. Only O. galili and W. microcarpae were present in the South African figs. Fig wasp species richness within individual figs was also significantly higher in China, with an average of around three species in each fig, compared with less than two species per fig in South Africa and Spain (Tables $2 \& 3$ ).

E. verticillata was the predominant species in Spain and China, where it was present in more than $70 \%$ of the figs and comprised more than half of the fig wasp individuals (Table 4). Its abundance in the figs it occupied was significantly higher in China than Spain, despite the numerous putative parasitoids and competitor NPFW sharing the Chinese figs (Tables $3 \& 4$ ). In the absence of the pollinator, W. microcarpae was the more common species in South Africa, where it occupied over $90 \%$ of the figs, and comprised over $90 \%$ of the individual fig wasps present (Tables $3 \& 4$ ). In China and Spain it occupied fewer figs and was present at lower densities in the figs that it occupied. In contrast, O. galili was present in fewer of the figs in South Africa than elsewhere and was also present at lower densities per occupied fig (Tables $3 \& 4$ ).

Mean numbers of female flowers (potential oviposition sites) within the F. microcarpa figs varied from about 140 to 200 (Table 2). Combined occupancy rates of female flowers were about 10\% in Spain and less than $4 \%$ in South Africa (Tables $2 \& 3$ ). Although the numbers of fig wasp individuals within each fig were higher in China than in Spain or South Africa, only around $25 \%$ of the flowers in the figs there had been galled.

\section{Male-free figs and trapped females}


High frequencies of figs containing female fig wasps but no males (of any species) were found in South Africa (19.9\%), compared with 4.5\% and 3.6\% of the figs in Spain and China respectively (Tables $1 \& 3$ ).

The fallen figs collected beneath ten F. microcarpa trees in Grahamstown included figs that had aborted without being colonised and 148 figs that contained ovules galled by fig wasps. Fig wasps had emerged from most of these figs, but 4.1\% (O. galili) and $16.9 \%$ (W. microcarpae) lacked exit holes and contained only trapped dead females (none contained females of both species). These values were similar to those obtained from the 140 figs collected directly from the trees in Grahamstown, where $1.4 \%$ and $17.9 \%$ of the figs contained O. galili or W. microcarpae females, but no males of either species, respectively (GLMM (binomial): O. galili: $\mathrm{df}=1, \mathrm{LR}=1.919, \mathrm{p}=0.166 ; W$. microcarpae: $\mathrm{df}=1, \mathrm{LR}=0.042, \mathrm{p}=0.837$ ). This shows that females of both NPFW rarely if ever escape from their natal figs without the aid of males.

\section{Sex ratios}

Sex ratios were female-biased, except for O. galili in China (Table 4). For each species there was a significant positive relationship between the probability that a fig contained conspecific males and the density of that species, and this trend did not vary among countries (Table 5; Fig. 2). For each species, females and conspecific males always cooccured in figs containing six or more conspecifics (Table 5; Fig. 2). O. galili and W. microcarpae females are able to emerge and mate with males from other figs, but pollinator females do not have this option, and when at low densities in occupied figs were liable to remain un-mated. The proportions of figs containing females but no conspecific males did not vary significantly among countries (Tables $3 \& 6$ ).

\section{Inter-specific facilitation}

In Spain and China, male E. verticillata was absent from only two of the figs that contained this species (around 1\%), so female NPFW were likely to be able to mate and 
escape from most of the figs. There was a significant positive relationship between numbers of NPFW males and NPFW species richness within individual figs in both Spain and China, suggesting that inter-specific facilitation of female-release increases with the species richness of the local fig wasp community (Table 5; Fig. 3).

In South Africa, $21.8 \%$ of the figs that contained W. microcarpae females had no conspecific males, which was close to the proportion that did not contain males of any species (20.4\%) (GLMM (binomial): $\mathrm{df}=1, \mathrm{LR}=0.143, \mathrm{p}=0.705$; Table 6). In contrast, many figs with $O$. galili females but no O. galili males did contain W. microcarpae males, and as a result only $7.4 \%$ of the figs occupied by this species were entirely malefree, despite the rarity of its own males (GLMM (binomial): $\mathrm{df}=1, \mathrm{LR}=4.676, \mathrm{p}=0.031$; Table 6). Consequently, the potential for facilitation between the two species was higher asymmetric, with the rarer species benefitting from sharing figs with the more common W. microcarpae. Assuming that $O$. galili females never manage to escape unaided by males, then they were only able to emerge from $22.2 \%$ of the figs they had occupied thanks to the help provided by W. microcarpae males.

\section{Discussion}

Fig wasps developing in figs of F. microcarpa within the plants native range are members of a diverse community. Pollinators are abundant, ovule occupation rates are relatively high, and almost all the figs contain males that can potentially contribute to the chewing of exit holes to let the female fig wasps escape. In Spain, the fig wasp community is less diverse, but the frequent presence of pollinators in the figs provides most females with a chance to escape. In South Africa, the depauperate and low density fig wasp community, and in particular an absence of pollinators, results in many more females being trapped in their natal figs. Frequencies of figs with no exit holes from beneath the trees that contained dead females matched those on the trees, confirming 
that a lack of males results in the deaths of the females. In the absence of pollinator males, the rarer NPFW in South Africa nonetheless benefitted from exit holes made by males of the more common NPFW.

Density compensation (where species in less-rich communities are present at higher densities within the figs they occupy) could potentially have reduced the risk of NPFWs developing in male-free F. microcarpa figs within the plant's introduced range. However, the densities of W. microcarpae and O. galili in Spain and South Africa were no higher than in the Chinese figs, and given that few or no other fig wasp species were present, this resulted in fig wasps as a whole exploiting far fewer of the female flowers in the figs away from the native range. The lack of density compensation may reflect environmental factors such as a less favourable climate in South Africa and Spain, but in South Africa will also have resulted from elevated mortality rates among the females that resulted from an absence of pollinators. Inverse density dependence, where population growth rates decline as density declines, influences the dynamics of many plant and animal populations, especially if they are recent colonists (Lande 1998; Courchamp, Clutton-Brock \& Grenfell 1999; Courchamp, Berec \& Gascoigne 2008; Tobin, Berec \& Liebhold 2011). The situation in South Africa provides an unusual example of this, because it occurs in combination with density dependent inter-specific facilitation, where one species benefits from higher densities of the other. The NPFW females that develop in figs that lack conspecific males but nonetheless escape with the aid of males of other species can mate on the outside of the figs, so no reproductive costs may be involved.

Fig wasps that become established on fig trees planted outside their natural range are surviving under conditions unlike those where they evolved, and aspects of their reproductive strategies appear to be sub-optimal. The increased numbers of figs that lacked males in South Africa and to a lesser extent in Spain resulted from an interaction between the lower densities of fig wasps in the figs and the reproductive strategies of 
the NPFW. Both the extent of aggregation (the small number of eggs laid by each female into one fig) and the female-biased sex ratios of the NPFWs contributed to the increased lack of males and seem inappropriate to the ecological situation to which the insects are currently being exposed.

Sex ratios vary widely among wasps in general, as do the clutch sizes laid by females on individual patches (Smart \& Mayhew 2009). Optimal oviposition strategies will be different in the introduced and native ranges of the two NPFW, because of the differences in the mix of species sharing the figs and their overall densities. Fig wasp parasitoids can concentrate their attacks on figs that contain more hosts (Suleman, Raja \& Compton 2013), which will have selected for increased dispersion of offspring across figs in the NPFW native range, but this is not a problem for the NPFW of F. microcarpa in Spain and South Africa, because parasitoids are absent. Along with less femalebiased sex ratios, a preference for oviposition into figs shared with other species would also be beneficial.

Intra-specific variation in traits associated with oviposition decisions are likely to have an inherited component, and be potentially subject to selection (Charnov \& Skinner1984; Godfray 1994; Greeff 1997). Models (Kanarek \& Webb 2010) suggest that adaptations mitigating against inverse density dependent effects among the small, sparse populations typical of founding populations occur at rates that are proportional to the genetic variation present in the populations. Both NPFW are likely to have arrived in South Africa in small initial numbers after a series of stepping stones involving several countries, rather than arriving directly from SE Asia (R Wang \& SG Compton unpublished). If confirmed, this suggests that adaptations that would facilitate successful NPFW emergence from the figs of F. microcarpa may occur relatively slowly, despite the strong selection pressures that are being generated.

\section{Acknowledgements}


We thank Dr Simon van Noort for helpful advice on fig wasps in South Africa. We also thank the China Scholarship Council (CSC) for the financial support of the PhD study of Rong Wang. Simon Segar was supported by the project Postdoc USB (reg.no. CZ.1.07/2.3.00/30.0006) through EU Education for Competitiveness Operational Programme. This project is funded by European Social Fund and Czech State Budget. 


\section{References}

Allee, W.C., Emerson, A.E., Park, O. \& Schmidt K.P. (1949) Principles of Animal Ecology. W.B. Saunders.

Bates, D., Maechler, M. \& Bolker, B. (2013) lme4: Linear mixed-effects models using S4 classes. R package version 0.999999-2.

Beardsley, W.J. (1998) Chalcid wasps (Hymenoptera: Chalcidoidea) associated with fruit of Ficus microcarpa in Hawaii. Proceedings of the Hawaiian Entomological Society, 33, 19-34.

Berg, C.C. \& Corner, E.J.H. (2005) Moraceae-Ficus, Flora Malesiana, Ser. I, Volume 17/Part2., pp. 289301. National Herbarium of the Netherlands, Leiden.

Bouček, Z. (1988) Australian Chalcidoidea (Hymenoptera): a biosystematic revision of genera of fourteen families, with a reclassification of species. CAB International, Wallingford.

Caughlin T., Wheeler J.H., Jankowski J. \& Lichstein J.W. (2012) Urbanized landscapes favored by figeating birds increase invasive but not native juvenile strangler fig abundance. Ecology, 93, 1571-1580.

Charnov, E.L. \& Skinner, S.W. (1984) Evolution of Host Selection and Clutch Size in Parasitoid Wasps. Florida Entomologist, 67, 5-21.

Chen, Y-R., Chuang, W-C. \& Wu, W-J. (1999) Chalcid wasps on Ficus microcarpa L. in Taiwan (Hymenoptera: Chalcidoidea). Journal of Taiwan Museum, 52, 39-79.

Compton, S.G. (1989) The fig wasp, Odontofroggatia galili (Hymenoptera: Pteromalidae), in the Greek Isles. Entomologist's Gazette, 40, 183-184.

Courchamp, F., Berec, L. \& Gascoigne, J. (2008) Allee Effects in Ecology and Conservation. Oxford University Press, Oxford.

Courchamp, F., Clutton-Brock, T. \& Grenfell, B. (1999) Inverse density dependence and the Allee effect. Trends in Ecology and Evolution,14, 405-409.

Dunn, D.W., Segar, S.T. , Ridley, J., Chan, R., Crozier, R.H., Yu, D.W. \& Cook, J.M. (2008) A role for parasites in stabilising the fig-pollinator mutualism. PLoS Biology, 6, e59.

Fellowes, M.D.E., Compton, S.G. \& Cook, J.M. (1999) Sex allocation and local mate competition in Old World non-pollinating figs wasps. Behavioral Ecology and Sociobiology, 46, 95-102.

Feng, G. \& Huang D-W. (2010) Description of a new species of Odontofroggatia (Chalcidoidea, Epichrysomallinae) associated with Ficus microcarpa (Moraceae) with a key to species of the genus. Zootaxa, 2335, 40-48.

Figueiredo, R.A.de. \& Motta Jr., J.C. (1993) Biology of Walkerella yashiroi (Hymenoptera, Chalcidoidea). Naturalia (Sao Paulo), 18, 27-32.

Galil, J. \& Copland, J.W. (1981) Odontofroggatia galili Wiebes in Israel, a primary fig wasp of Ficus microcarpa with a unique ovipositor mechanism (Epichrysomallinae, Chalcidoidea). Proceedings of the Koninklijke Nederlandse Akademie van Wetenschappen, Series C: Biological and Medical Sciences, 84, 183-195.

Galil, J. \& Eisikowitch, D. (1968) Flowering cycles and fruit types of Ficus sycomorus in Israel. New Phytologist, 67, 745-758.

Ghazoul, J. (2006) Floral diversity and the facilitation of pollination. Journal of Ecology, 94, 295-304.

Godfray, H.C.J. (1994) Parasitoids: Behavioural and Evolutionary Ecology. Princeton University Press, Princeton, New Jersey.

Greeff, J.M. (1997) Offspring allocation in externally ovipositing fig wasps with varying clutch size and sex ratio. Behavioral Ecology, 8, 500-505. 
Harrison, R.D. (2005) Figs and the diversity of tropical rainforests. Bioscience, 55, 1053-1064.

Heimpel, G.E. (1994) Virginity and the cost of insurance in highly inbred Hymenoptera. Ecological Entomology, 19, 299-302.

Kanarek, A.R. \& Webb, C.T. (2010) Allee effects, adaptive evolution, and invasion success. Evolutionary Applications, 3, 122-135.

Kaufmann, S., Mckey, D.B., Hossaert-Mckey, M. \& Horvitz, C.C. (1991) Adaptations for a two phase seed dispersal system involving vertebrates and ants in a hemiepiphytic fig (Ficus microcarpa: Moraceae). American Journal of Botany, 78, 971-977.

Keane, R.M. \& Crawley, M.J. (2002) Exotic plant invasions and the enemy release hypothesis. Trends in Ecology and Evolution, 17, 164-170.

Kerdelhué, C. \& Rasplus, J.Y. (1996) The evolution of dioecy among Ficus (Moraceae): an alternative hypothesis involving non-pollinating fig wasp pressure on the fig-pollinator mutualism. Oikos, 77, 163166.

Lande, R. (1998) Demographic stochasticity and Allee effect on a scale with isotropic noise. Oikos, 83, $353-358$.

László, Z. \& Tóthméréz, B. (2008) Optimal clutch size of the gall wasp Diplolepis rosae (Hymenoptera: Cynipidae). Entomologica Fennica, 19, 168-175.

Losey, J.E. \& Denno, R.F. (1998) Positive predator-predator interactions: enhanced predation rates and synergistic suppression of aphid populations. Ecology, 79, 2143-2152.

Miao, B-G., Yang, D-R., Liu, C., Peng, Y-Q. \& Compton, S.G. (2011) The impact of a gall midge on the reproductive success of Ficus benjamina, a potentially invasive fig tree. Biological Control, 59, 228-233. Moore, J.C., Zavodna, M., Compton, S.G. \& Gilmartin, P. (2005) Sex ratio strategies and the evolution of cue use. Proceedings of the Royal Society B: Biological Sciences, 272, 1287-1294.

Nadel, H., Frank, J.H. \& Knight Jr., R.J. (1992) Escapees and accomplices: The naturalisation of exotic Ficus and their associated faunas in Florida. Florida Entomologist, 75, 29-38.

R Development Core Team. 2013. R: A language and environment for statistical computing. R Foundation for Statistical Computing, Vienna, Austria.

Richardson, D.M., Allospp, N., D'Antonio, C.M., Milton, S.J. \& Rejmánek, M. (2000) Plant invasions the role of mutualisms. Biological Reviews, 75, 65-93.

Shanahan, M., So, S., Compton, S.G. \& Corlett, R. (2001) Fig-eating by vertebrate frugivores: a global review. Biological Review, 76, 529-572.

Smart, C.B. \& Mayhew, P.J. (2009) A Comparative Study of Sex Ratio and Clutch Size in Gregarious Ichneumonoid Wasps. Journal of Insect Behavior, 22, 273-288.

Soler, R., Badenes-Pérez, F.R., Broekgaarden, C., Zheng, S-J., David, A., Boland, W. \& Dicke, M. (2012) Plant-mediated facilitation between a leaf-feeding and a phloem-feeding insect in a brassicaceous plant: from insect performance to gene transcription. Functional Ecology, 26, 156-166.

Stange, L.A. \& Knight, R.J. Jr. (1987) Fig pollinating wasps of Florida (Hymenoptera: Agaonidae). Florida Department of Agriculture \& Consumer Services Division of Plant Industry: Entomology Circular No. 296: 1-4.

Starr, F., Starr, K. \& Loope, L. (2003) Ficus microcarpa Chinese banyan Moraceae. Available from: http://www.hear.org/starr/hiplants/reports/pdf/ficus_microcarpa.pdf.

Starzomski, B.M., Suen, D. \& Srivastava, D.S. (2010) Predation and facilitation determine chironomid emergence in a bromeliad-insect food web. Ecological Entomology, 35, 53-60. 
Suleman, N., Raja, S. \& Compton, S.G. (2012) Only pollinator fig wasps have males that collaborate to release their females from figs of an Asian fig tree. Biology Letters, 8, 344-346.

Suleman, N., Raja, S. \& Compton, S.G. (2013) Parasitism of a pollinator fig wasp: mortalities are higher in figs with more pollinators, but are not related to local densities of figs. Ecological Entomology, 38, 478-484.

Sun, X-J., Xiao, J-H., Cook, J.M., Feng, G. \& Huang, D-W. (2011) Comparisons of host mitochondrial, nuclear and endosymbiont bacterial genes reveal cryptic fig wasp species and the effects of Wolbachia on host mtDNA evolution and diversity. BMC Evolutionary Biology, 11, 86-93.

Tobin, P.C., Berec, L.K. \& Liebhold, A.M. (2011) Exploiting Allee effects for managing biological invasions. Ecology Letters, 14, 615-624.

Tylianakis, J.M., Didham, R.K., Bascompte, J. \& Wardle, D.A. (2008) Global change and species interactions in terrestrial ecosystems. Ecology Letters, 11, 1351-1363.

van Noort, S., Wang, R. \& Compton, S.G. (2013) Fig wasps (Hymenoptera: Chalcidoidea: Agaonidae, Pteromalidae) associated with Asian fig trees (Ficus, Moraceae) in South Africa: Asian followers and African colonists. African Invertebrates, 54, 381-400.

Wang, R., Matthews, A., Ratcliffe, J., Barwell, L., Peng, Y-Q., Chou, L-S., Yu, H.., Yang, H-W..\& Compton, S.G. (2014) First record of an apparently rare fig wasp feeding strategy: obligate seed predation. Ecological Entomology, first published online: 30 May 2014.

Wiebes, J.T. (1979) Co-evolution of figs and their insect pollinators. Annual Review of Ecology and Systematics, 10, 1-12.

Yu, H. \& Compton, S.G. (2012) Moving your sons to safety: galls containing male fig wasps expand into the centre of figs, away from enemies. PLoS ONE, 7, ARTN e30833. 
Table 1. Locations of samples of mature figs of F. microcarpa.

\begin{tabular}{|c|c|c|c|c|c|}
\hline Country & Site & Sampling date & Co-ordinates & $\begin{array}{c}\mathrm{N} \\
\text { crops }\end{array}$ & $\begin{array}{c}\mathrm{N} \\
\text { figs }\end{array}$ \\
\hline South Africa & Grahamstown & April 2011 and 2012 & $\mathrm{~S} 33^{\circ} 56^{\prime}$, E $25^{\circ} 34^{\prime}$ & 7 & 140 \\
\hline South Africa & Port Elizabeth & April 2011 and 2012 & $\mathrm{~S} 33^{\circ} 19^{\prime}, \quad$ E $26^{\circ} 31^{\prime}$ & 5 & 81 \\
\hline Spain & Majorca & September 2012 & $\mathrm{~N} 39^{\circ} 38^{\prime}, \quad$ E $3^{\circ} 02^{\prime}$ & 6 & 112 \\
\hline China & Guangzhou & September 2011 and 2012 & $\begin{array}{r}\mathrm{N} 23^{\circ} 08^{\prime}, \quad \mathrm{E} \\
113^{\circ} 16^{\prime}\end{array}$ & 12 & 169 \\
\hline
\end{tabular}


Table 2. The contents of mature F. microcarpa figs (means $\pm \mathrm{SE}$ ) in three countries. Note that female flower numbers were not recorded for all figs. Ovule occupancy is the proportion of total female flowers that contained fig wasp adult offspring.

\begin{tabular}{lccccccc}
\hline \multicolumn{1}{c}{ Country } & Crops & $\begin{array}{c}\text { Species richness } \\
(\mathrm{N} \text { figs })\end{array}$ & $\begin{array}{c}\text { Fig wasp } \\
\text { abundance } \\
\text { (N figs) }\end{array}$ & $\begin{array}{c}\text { Female flowers } \\
\text { (N figs) }\end{array}$ & $\begin{array}{c}\text { Ovule occupancy } \\
\text { per fig (\%) (N } \\
\text { figs) }\end{array}$ & $\begin{array}{c}\text { Total male fig } \\
\text { wasps (N figs) }\end{array}$ & $\begin{array}{c}\text { Figs with no } \\
\text { male fig wasps } \\
(\%)(\mathrm{N} \text { figs) }\end{array}$ \\
\hline South Africa & 12 & $1.08 \pm 0.02(221)$ & $6.5 \pm 0.4(221)$ & $180.1 \pm 3.3(181)$ & $3.7 \pm 0.3(181)$ & $2.0 \pm 0.2(221)$ & $19.9(44)$ \\
Spain & 6 & $1.46 \pm 0.08(112)$ & $19.8 \pm 1.4(112)$ & $199.3 \pm 3.6(112)$ & $10.1 \pm 0.7(112)$ & $5.1 \pm 0.4(112)$ & $4.5(5)$ \\
China & 12 & $3.05 \pm 0.12(169)$ & $35.9 \pm 2.1(169)$ & $144.4 \pm 2.8(169)$ & $26.2 \pm 1.3(169)$ & $9.9 \pm 0.6(169)$ & $3.6(6)$ \\
\hline
\end{tabular}


Table 3. Among-countries comparisons of species richness, occupancy rates, the abundance of E. verticillata, O. galili and W. microcarpae, and the proportions of figs with no male fig wasps and those containing either O. galili or W. microcarpae but no conspecific males. GLMMs assumed either binomial (B) or Poisson (P) distributions of residuals. $\mathrm{LR}=$ Likelihood ratio.

\begin{tabular}{|c|c|c|c|c|c|c|}
\hline Response variable & Effect & Model & Df & LR & Pair-wise Comparison & $\mathrm{Z}$ value \\
\hline \multirow[t]{3}{*}{ Species richness } & Country & GLMM (P) & 2 & $37.996^{* * *}$ & South Africa vs. Spain & $-1.898^{\mathrm{NS}}$ \\
\hline & & & & & South Africa vs. China & $-8.778^{* * *}$ \\
\hline & & & & & Spain vs. China & $-5.475^{* * *}$ \\
\hline \multirow[t]{3}{*}{ Ovule occupancy } & Country & GLMM (B) & 2 & $47.292^{* * *}$ & South Africa vs. Spain & $-4.572^{* * *}$ \\
\hline & & & & & South Africa vs. China & $-10.725^{* * *}$ \\
\hline & & & & & Spain vs. China & $-4.252^{* * *}$ \\
\hline E. verticillata abundance & Country & GLMM (P) & 1 & $5.594^{*}$ & Spain vs. China & $-2.599^{* *}$ \\
\hline \multirow[t]{3}{*}{ O. galili abundance } & Country & GLMM (P) & 2 & $15.433^{* * *}$ & South Africa vs. Spain & $-4.788^{* * *}$ \\
\hline & & & & & South Africa vs. China & $-2.207^{\mathrm{NS}}$ \\
\hline & & & & & Spain vs. China & $3.033^{* *}$ \\
\hline \multirow[t]{3}{*}{ W. microcarpae abundance } & Country & GLMM (P) & 2 & $3.657^{\mathrm{NS}}$ & South Africa vs. Spain & $-1.875^{\mathrm{NS}}$ \\
\hline & & & & & South Africa vs. China & $0.061^{\mathrm{NS}}$ \\
\hline & & & & & Spain vs. China & $1.778^{\mathrm{NS}}$ \\
\hline Proportion of figs & Country & GLMM (B) & 2 & $13.675^{* *}$ & South Africa vs. Spain & $2.685^{*}$ \\
\hline containing no male fig & & & & & South Africa vs. China & $3.479^{* *}$ \\
\hline wasps & & & & & Spain vs. China & $0.386^{\mathrm{NS}}$ \\
\hline Proportion of figs & Country & GLMM (B) & 2 & $2.027^{\mathrm{NS}}$ & South Africa vs. Spain & $-1.301^{\mathrm{NS}}$ \\
\hline containing $O$. galili but no & & & & & South Africa vs. China & $-1.255^{\mathrm{NS}}$ \\
\hline conspecific males & & & & & Spain vs. China & $0.046^{\mathrm{NS}}$ \\
\hline Proportion of figs & Country & GLMM (B) & 2 & $0.486^{\mathrm{NS}}$ & South Africa vs. Spain & $-0.284^{\mathrm{NS}}$ \\
\hline containing W. microcarpae & & & & & South Africa vs. China & $-0.663^{\mathrm{NS}}$ \\
\hline but no conspecific males & & & & & Spain vs. China & $-0.187^{\mathrm{NS}}$ \\
\hline
\end{tabular}

NS: not significant, ${ }^{*}: \mathrm{p}<0.05,{ }^{* *}: \mathrm{p}<0.01$ and ${ }^{* * *}: \mathrm{p}<0.001$. 
Table 4. Prevalence, abundance and sex ratios (proportion males) (means \pm SE) of the three fig wasps. Note that sexes were not assessed in all the figs, so some sample sizes differ from abundance counts. Fig wasp abundance was calculated only for figs where that species was present.

\begin{tabular}{lrrr}
\hline \multicolumn{1}{c}{ Country } & $\begin{array}{c}\text { Prevalence (\%) } \\
\text { (N figs) }\end{array}$ & \multicolumn{1}{c}{$\begin{array}{c}\text { Fig wasp } \\
\text { abundance }\end{array}$} & Sex ratio \\
\hline South Africa & & & \\
O. galili & $12.2(27)$ & $3.3 \pm 0.6$ & $0.38 \pm 0.07$ \\
W. microcarpae & $95.5(211)$ & $6.3 \pm 0.4$ & $0.33 \pm 0.02$ \\
Spain & & & \\
E. verticillata & $72.3(81)$ & $15.2 \pm 1.2$ & $0.21 \pm 0.01$ \\
O. galili & $42.9(48)$ & $13.4 \pm 1.3$ & $0.29 \pm 0.02$ \\
W. microcarpae & $17.9(20)$ & $8.6 \pm 1.2$ & $0.32 \pm 0.04$ \\
China & & & \\
E. verticillata & $75.1(127)$ & $32.3 \pm 2.4$ & $0.26 \pm 0.01$ \\
O. galili & $27.8(47)$ & $5.6 \pm 1.0$ & $0.58 \pm 0.06$ \\
W. microcarpae & $24.3(41)$ & $4.6 \pm 0.9$ & $0.40 \pm 0.05$ \\
\hline
\end{tabular}


Table 5. Between and within-country comparisons of the presence of male fig wasps in F. microcarpa figs in relation to fig wasp densities. GLMMs assumed either binomial (B) or Poisson (P) distributions of residuals.

\begin{tabular}{|c|c|c|c|c|c|c|c|}
\hline Response variable & Effect & Model & df & LR & Country & $\beta($ mean $\pm \mathrm{SE})$ & LR of $\beta$ \\
\hline Probability of figs & O. galili abundance $\times$ Country & GLMM (B) & 2 & $5.365^{\mathrm{NS}}$ & South Africa & $1.269 \pm 0.618$ & $10.695^{* *}$ \\
\hline containing $O$. galili with & & & & & Spain & $0.697 \pm 0.268$ & $23.663^{* * *}$ \\
\hline conspecific male(s) & & & & & China & $0.293 \pm 0.165$ & $4.676^{*}$ \\
\hline Probability of figs & W. microcarpae abundance $\times$ Country & GLMM (B) & 2 & $0.541^{\mathrm{NS}}$ & South Africa & $0.756 \pm 0.155$ & $64.480^{* * *}$ \\
\hline containing W. microcarpae & & & & & Spain & $1.222 \pm 0.912$ & $10.826^{* *}$ \\
\hline with conspecific male(s) & & & & & China & $0.620 \pm 0.364$ & $5.706^{*}$ \\
\hline \multirow[t]{2}{*}{ Number of NPFW males } & NPFW species richness $\times$ Country & GLMM (P) & 2 & $0.794 \mathrm{NS}$ & Spain & $0.242 \pm 0.087$ & $7.401^{* *}$ \\
\hline & & & & & China & $0.330 \pm 0.029$ & $120.51^{* * *}$ \\
\hline
\end{tabular}


Table 6. Proportions of figs containing W. microcarpae or O. galili females but no conspecific males or no males of any fig wasp species.

\begin{tabular}{lcccc}
\hline Countries & $\begin{array}{c}\text { Figs with female but } \\
\text { no male } \\
\text { O. galili(\%) }\end{array}$ & $\begin{array}{c}\text { Figs with female } \\
\text { but no male } \\
\text { W. microcarpae(\%) }\end{array}$ & $\begin{array}{c}\text { Figs with female } O \text {. } \\
\text { galili but no male fig } \\
\text { wasps (\%) }\end{array}$ & $\begin{array}{c}\text { Figs with female } W . \\
\text { microcarpae but no } \\
\text { male fig wasps (\%) }\end{array}$ \\
\hline South Africa & (N figs) & (N figs) & (N figs) & (N figs) \\
Spain & $29.6(27)$ & $21.8(211)$ & $7.4(27)$ & $20.4(211)$ \\
China & $16.7(8)$ & $20.0(4)$ & $6.3(3)$ & $0(0)$ \\
\hline
\end{tabular}

For consistency Cut the line separating $\mathrm{N}$ figs from above 

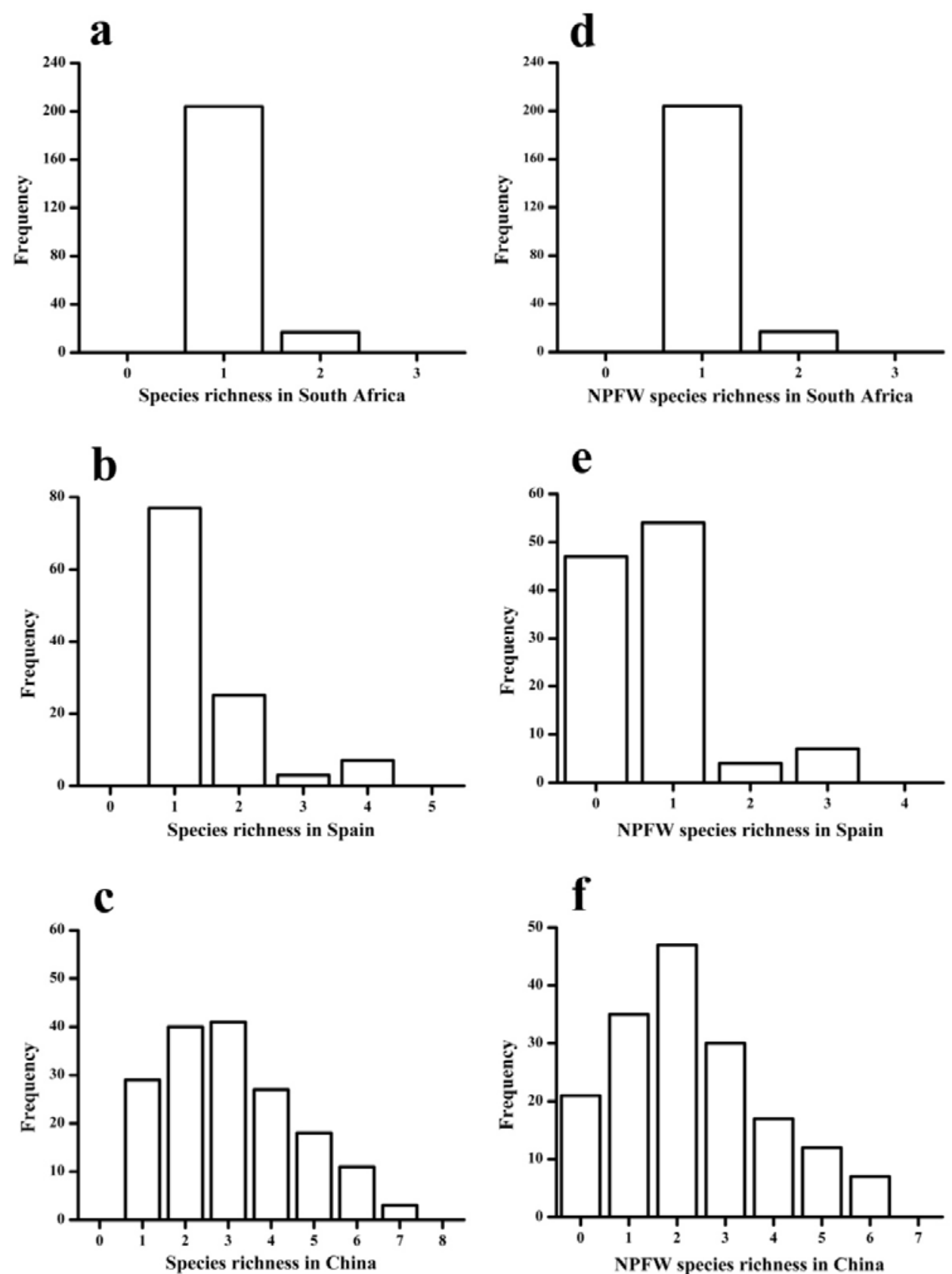

Fig. 1. The distribution of fig wasp species richness per fig (a-c) and NPFW species richness (d-f) in three countries. 




Fig. 2. Generalized linear functions reflecting relationships between the probability of a fig containing either O. galili (a) or W. microcarpae (b) with conspecific males and the abundance of that species in F. microcarpa figs in South Africa (black line), Spain (grey line) and China (light grey line). Individual figs are represented by black squares (South African figs), grey triangles (Spanish figs) and light grey circles (Chinese figs). 


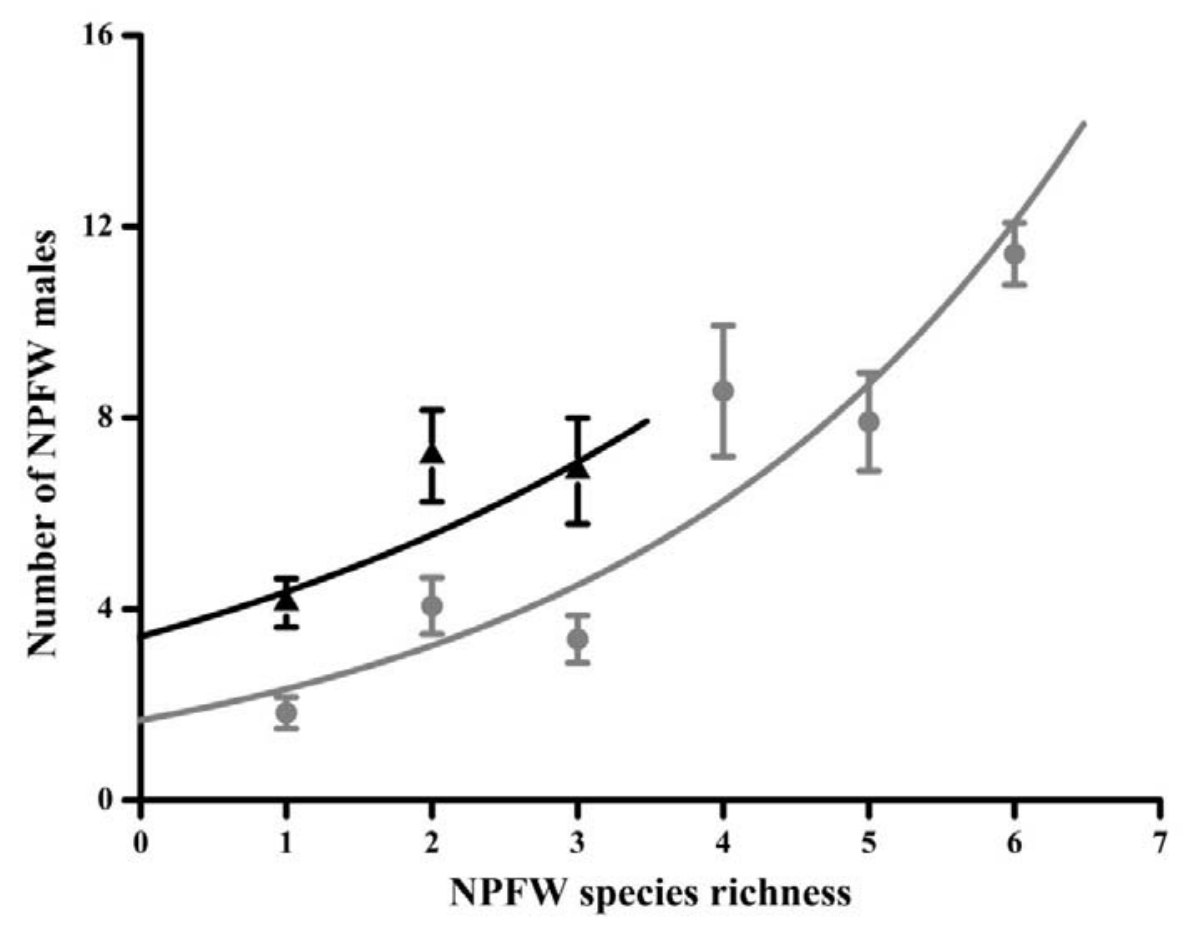

Fig. 3. Generalized linear functions reflecting relationships between numbers of NPFW males and NFPW species richness in Spain (black line) and China (grey line). Few figs contained more than one species in South Africa.Number of NPFW males (mean $\pm \mathrm{SE}$ ) was summarized in every number of NPFW species richness.

Cut this and replace $\mathrm{Y}$ axis label with 'NPFW males (mean $\pm \mathrm{SE}$ )' 